some inconvenience; it is not necessary $t$, know the English grammar to scrub floors."

There is some truth in that, but several objections to Dr. Osborne's letter come to my mind:

(1) Three years' training entitle a medical auxiliary in the N.H.S. to higher salary than two years. Physiotherapists who train for three years are better paid than we radiographers for that reason alone.

(2) A radiographer after two years' training is not in my opinion ready to work alone as she does on night duty. She must have experience which she does not always get during her two years' studies. Nearly all radiographers attain the required standard by asking questions, observing, and making mistakes. Why then should a radiographer acquire her knowledge by "do-it-yourself" methods in an age when more and more facilities are given to young people for their technical education?

(3) Latest statistics show an increase in the male population as compared with the female. Therefore it is likely that more radiographers will marry earlier, and you might have to rely on males, and pay them

(4) There are now other technical jobs open to women with intelligence and a scientific turn of mind, and far better pay and prospects in commerce and industry.

It seems obvious to me that radiography must be glamorized or turn full circlethat is, the radiologist taking the pictures, the nurse handing him the cassettes, the porters looking after the dark-rooms, as is still the case in many hospitals on the Continent. I am, etc.,

Loughton, Essex.

Rosa SOLdINGer.

\section{Artificial Respiration}

SIR,-Although mouth-to-mouth respiration is considered a modern technique it has been described many times in the past.

I feel, however, that your readers may be interested in the following passage from a chapter on recovery of drowned persons, written by J. Baker, M.D., in Domestic Medicine: or a Treatise on the Prevention and cure of diseases, by William Buchan, M.D., F.R.C.P.(Ed.), a controversial book of the period published in 1806 (1st ed. 1760 approx.).

"A perfon fhould blow with all his force into the patient's mouth, holding his noftrils at the fame time. When from the rifing of the cheft or belly it appears that the lungs are filled with air, the blowing fhould be fufpended, and the perfon prefs the breaft and belly, fo as to difpel it ; and alternately inflate and deprefs the lungs in this manner for fome time, fo as to imitate natural breathing. Or a pair of bellows or blow-pipe may be ufed, more powerfully than the mouth (but not fo efficacious in other refpects), ftopping the noftrils as much as pomble."

This seems a remarkable description of this form of artificial respiration, and possibly it fell into disrepute due to the fastidiousness of the physicians of the time, although a clue to the failure of the technique is provided by a section from instructions for treatment of the drowned circulated by the Royal Humane Society at about that time. The first of these was "Convey carefully the body, with the head raised, to the nearest convenient house."
There then follow four further procedures, including warming the body and rubbing it with spirits and stimulating mixtures, before artificial respiration was commenced. It is not surprising that recovery from drowning was rare.-I am, etc.,

$$
\begin{aligned}
& \text { Department of Nutrition, } \\
& \text { Queen Elizabeth College, } \\
& \text { London W.8. }
\end{aligned}
$$

A. J. SAlter.

\section{Holyrood Bursary Fund}

SIR,-All of us are aware that there are certain deficiencies in the National Health Service which still require voluntary effort and individual initiative to overcome them. One is the provision without hospitalization of psychotherapy for patients temporarily unable to earn their ordinary living through severe neurosis. Under the National Health Service at present it is difficult to obtain adequate therapy through dearth of facilities.

To help this situation, and because of a firm belief in the therapeutic value of living in a suitable community free from the hospital atmosphere, a centre known as Holyrood was created eight years ago with the help of the now Dean of Westminster. At this centre patients receive individual psychotherapy, the necessary medical and nursing care, and opportunity for painting, modelling, and other arts with a therapeutic intention. In this way they are gradually rehabilitated by incorporation into the working community until such time as they are fit to stand entirely on their own feet.

Unfortunately, this type of work costs more than most patients can afford to pay, even though the centre is run as economic- ally as possible and indeed at personal sacrifice on the part of the staff. Many patients in the past have been able to pay only a fraction of what their residence costs, taking out the balance in work, but it has now become necessary to take a serious look at the future financing of the organization, which at present has accommodation for 35 people.

A Holyrood Bursary Fund has therefore been opened seeking donations towards target of $£ 50,000$, the income from which will be used to make a stay at Holyrood possible for people who cannot afford normal fees. The centre is registered as a charity and therefore covenanted gifts are particularly welcome. Donors can be assured that they are subscribing to a unique institution which has, in its eight years of existence, shown considerable success in dealing with severe breakdowns in living and which is run with the greatest administrative economy.

Holyrood's President is the Bishop of Oxford and it is administered by a council and advised by a distinguished medical committee. We should add that although it is Anglican in background patients of all denominations, and indeed of no religious belief, are accepted.

May we appeal to the generosity of your readers and ask that all inquiries about the appeal be addressed to the Anpeal Secretary, Holyrood, South Leigh, Witney, Oxon. Telephone No. Witney 325.-We are, etc.,

Liphook, Hants. CeCIL WaKeley.

St. Mary's Hospital, J. D. W. Pearce.

London. Warden and Psychiatrist.

\section{Difficulty with Vacuum Extractor}

Dr. M. O. Grant (Leeds 9) writes: Recently while using the vacuum extractor I was puzzled by the readiness with which air was sucked under the cup on applying traction. On full inspection of both apparatus and infant afterwards the only possible explanation I could find was the presence of an unusually luxuriant growth of foetal hair. If this explanation be valid, I am not aware of having heard mention of it before, and should be most interested to know if anyone else has experienced this difficulty.

\section{Angor Animi}

Dr. J. M. MORRISON (Stirling) writes: I read with interest Dr. J. C. Barker's letter "Angor Animi" (12 September, p. 688). I have once observed the sudden death of an apparently healthy man which was preceded by undoubted angor animi. About four years ago as a medical student in Edinburgh I was assisting a houseofficer in the casualty department of the Royal Infirmary. $\dot{A}$ man in his sixties had been admitted with a four-hour history of mild central chest pain. Together we took his history and examined him, but found no abnormal physical signs. We were standing on either side of the examination trolley deciding what to do with him, when he suddenly grasped each of us by the arm. A look of intense fear had come into his eyes and he cried, "I'm away, Doctor, I'm away!" Following this he began to breathe in a manner closely simulating hysterical overbreathing, all the while staring at us with a fixed look of horror. In the few seconds during which this occurred we had time to say: "Come on, man, pull yourself together!" Shortly after this his breathing ceased abruptly, a wave of cyanosis spread like a blush frors neck to face, froth appeared at his lips, and the grip on our arms slackened. We were dumbfounded. The house-officer, thinking in terms of an epileptic fit, ran to get an air-way. He was dead. Our efforts to resuscitate him were fruitless.

Like Dr. Barker, I did not learn the necropsy findings, but have no doubt that he died of acute cardiac failure, resulting from infarction or fibrillation, and, what is more, that during those last few seconds he was aware of his "imminent dissolution."

\section{Doctors' Wive}

Mrs. URSULA WARREN (Southminster, Essex) writes: Mrs. Sylvia Golledge in her letter (29 August, p. 576) writes very casually of organizing a strike of general practitioner's wives. What nonsense this is. How can we supposedly responsible women behave in this way? I am content with my life, believing that the compassion shown to patients brings its own reward. There are, I am sure, many wives who think as I do, and who would play no part in Mrs. Golledge's schemes.

Correction.-We regret an error in the letter on "Prolonged Arteriospasm after Ergotamine" by Drs. E. A. Cameron and E. B. French (3 October, p. 875). The first sentence in the final paragraph should have read, "We believe that migraine confers no immunity to possible side-effects from ergotamine, and further that the route of administration is probably of little importance." 